\title{
Epigenetics and epigenomics: the future of nutritional interventions?
}

\author{
Bethan Hussey* ${ }^{*}$, Martin R Lindley ${ }^{1}$ \& Sarabjit Mastana ${ }^{1}$ \\ ${ }^{1}$ Translational Chemical Biology Research Group, School of Sport Exercise \& Health Sciences, Loughborough University, \\ Loughborough, UK \\ * Author for correspondence: B.C.L.Lockett@Lboro.ac.uk
}

\section{"Nutri-epigenomics looks to delineate the interactions between the diet and the genome through epigenetic mechanisms."}

First draft submitted: 10 July 2017; Accepted for publication: 17 July 2017; Published online: 15 August 2017

Keywords: DNA methylation • epigenetics $\bullet$ personalized nutrition

For many years, it was thought that sequencing the human genome would hold the answer to health and disease. However, after years of research and billions of dollars of funding, the Human Genome Project provided us with the script for the human genome, but not the great leap in understanding for genetic medicine that was anticipated. We still have many questions, particularly how the genome interacts with the environment to result in disease in some individuals, but not in others. For this we need to focus on the epigenome. In the 1940s, the epigenetic landscape began to take shape; famously described by Waddington [1], it explained how cells with the same genetic code could differentiate into the vast array of cells within an organism, connecting the genotype with the phenotype. The field of 'epigenetics', literally meaning 'above genetics', investigates chemical modifications to DNA that do not alter the gene sequence itself [2]. Epigenetic mechanisms, such as chromatin remodeling, histone modifications, DNA methylation and microRNAs, alter how the genome is expressed. These modifications can be enduring and passed through generations, but they can also be transient, allowing cells to adapt to the environment. In recent years, there has been an exponential increase in the research and knowledge within the field of epigenetics. It is only now that we are beginning to piece together interactions between the genome and epigenome with the environment to comprehend the implications for health and disease. A key environmental factor that we are exposed to from preconception to death is our diet. Nutri-epigenomics looks to delineate the interactions between the diet and the genome through epigenetic mechanisms.

The susceptibility of the epigenome to adapt to environmental factors alters across the lifespan of an organism, during which there are periods when the epigenome is more responsive to change [3]. Increased activity of the epigenome occurs in the prenatal and neonatal phases when cell differentiation and specialization is occurring. Environmental factors, such as nutrition, therefore have more influence during this period of development. In nature this mechanism is utilized by the honeybee, they feed genetically identical larvae royal jelly to alter DNA methylation patterns with the result of differentiation to either a queen or a worker bee [4]. In humans, the Developmental Origins of Health and Disease hypothesis explains how abnormalities within the developmental environment can affect the writing of the epigenome and lead to metabolic disease later in life [5]. It is understood that maternal stress, birth weight and fetal malnutrition (undernutrition and maternal obesity) contribute to an abnormal developmental environment and modifications to the epigenome, and as a result, can be enduring throughout the lifespan and passed on to the next generation. In mammals, malnutrition of methyl donors vitamin $\mathrm{B}_{12}$ and choline during gestation can lead to epigenetic dysregulation within the offspring, leading to obesity and influencing disease in later life [6]. Providing a favorable developmental environment through the use of nutritional supplements or a specific gestational diet could result in beneficial epigenetic changes. For example, supplementation with omega-3 fatty acids during gestation has been shown to protect against demethylation caused by the negative behavior of smoking [7]. Looking to the future, is developing an 'epigenetically healthy' gestational diet the answer to reducing the burden of chronic disease in later life and within our offspring? Future research must consider the 
hereditary nature of epigenetic signatures, with studies requiring observation of multiple generations. There must also be consideration for the long-term epigenetic impact of in vitro fertilization (IVF), where the early stages of development receive nutrients from outside of the mother.

Convincing individuals to maintain an 'epigenetically healthy' diet in order to benefit the health of their children and grandchildren is often not effective as there is no immediate beneficial effect seen by the individual. Therefore, research into the short-term effects of diet on the epigenome is required in adults. Aberrant alterations to epigenetic regulation is implicated as the cause of multiple chronic diseases including cancer, chronic obstructive pulmonary disease, cardiovascular disease, obesity, neurological disorders and Type-2 diabetes, to name a few. These changes in the epigenome provide therapeutic targets for intervention. Drugs have been developed to target epigenetic regulating enzymes, such as DNMT, HDAC and HAT inhibitors in order to reverse the changes to the epigenome. Discussed in a mini-review series in Clinical Epigenetics [8], there is a huge potential for epigenetic drugs; however, there is a long way to go before we truly understand their impact, particularly their wider alterations to the epigenome. Nutritional interventions or dietary supplementation may therefore provide a safer approach to prevent or reset these aberrant changes by influencing the natural epigenetic response within cells.

Personalized medicine and interventions are now common with the use of genotyping an individual in order to distinguish if they are a responder or a nonresponder to drugs and nutritional interventions. There has also been an increase in the use of genetic testing to identify targeted populations and interventions that will reduce the burden of disease in later life [9]. However, there is building evidence that epigenetic signatures could also be used to personalize interventions and predict response status. For example, it has been found that determining an 'epigenotype' for an individual can predict whether they are going to be a weight-loss responder to a calorie restricted diet [10]. We therefore must also consider the effect of the epigenome on nutritional requirements. Data such as this may be used to combine both genotype and epigenotype of an individual to assess their risk status for disease and response to nutritional interventions.

Implementation of epigenetic analysis to nutritional studies has barriers that must be considered, including technical and cost limitations. Careful consideration must be taken when choosing the sample for epigenetic analysis. Epigenetic control of the genome is cell specific and conversely, this means that alterations in response to the environment will be individual to tissue type and to individual cells within the tissue. Therefore, selecting an easily accessible tissue such as blood for analysis may lead to misleading findings due to the heterogeneity of cells and care must be taken when inferring conclusions from the sample tissue to the desired tissue of interest. Additionally the tissue composition must be accounted for, changes to tissue composition as a result of an intervention may lead to critical results being masked or exaggerated without specificity to one cell type or adjustment for any change [11]. Establishing causation is often an issue in epigenetic research, although there have been statistical methods employed to delineate causation [12], and carefully designed and controlled research is vital. Considerations into the biological relevance of statistically significant results must be supported by phenotypic data such as gene expression and protein profiles. Epigenetic control of the genome is far more complicated than first thought with a multitude of different epigenetic mechanisms to quantify, plus their interactions with each other. For example, considering DNA methylation alone, there are multiple modifications in the chemistry to cytosine other than the heavily studied methylcytosine, including hydroxymethylcytosine, formylcytosine and carboxycytosine, that cannot currently be resolved through the bisulfite sequencing methods. Methods to quantify these other cytosine modifications are being developed but currently not concordant with each other or available for whole genome use [13]. Due to the complexity of the epigenome, many of the technologies used to measure its epigenetic makeup come at a high cost. Institutions and funding bodies must 'buy in' to running these high cost assays in order to gain additional information from their nutritional research.

\section{Conclusion}

Given the interactions between nutrition and the epigenome, future work in this field has the potential to provide a rewarding benefit for public health. If we want to understand how our body responds to nutritional interventions then we need to understand the interactions with the genome and epigenome. Understanding these modifications, which can be passed through generations, will provide vital knowledge to thwarting noncommunicable diseases and promoting healthy free living in later life. We have the potential to impact on the evolution of the human species by tailoring our diets to alter/maintain the epigenome. 
Financial \& competing interests disclosure

The authors have no relevant affiliations or financial involvement with any organization or entity with a financial interest in or financial conflict with the subject matter or materials discussed in the manuscript. This includes employment, consultancies, honoraria, stock ownership or options, expert testimony, grants or patents received or pending, or royalties.

No writing assistance was utilized in the production of this manuscript.

\section{Open access}

This work is licensed under the Creative Commons Attribution-NonCommercial 3.0 Unported License. To view a copy of this license, visit http://creativecommons.org/licenses/by-nc-nd/4.0/

\section{References}

1 Waddington CH. The epigenotype. Int. J. Epidemiol. 41(1), 10-13 (2012).

2 Bernstein BE, Meissner A, Lander ES. The mammalian epigenome. Cell 128(4), 669-681 (2007).

3 Kanherkar RR, Bhatia-dey N, Csoka AB. Epigenetics across the human lifespan. Front. Cell. Dev. Biol. 2, 1-19 (2014).

4 Kucharski R, Maleszka J, Foret S, Maleszka R. Nutritional control of reproductive status in honeybees via DNA methylation. Science 319(5871), 1827-1830 (2008).

5 Gluckman PD, Hanson MA. Developmental origins of disease paradigm: a mechanistic and evolutionary perspective. Pediatr. Res. 56(3), 311-317 (2004).

6 Waterland RA, Jirtle RL. Transposable elements: targets for early nutritional effects on epigenetic gene regulation. Mol. Cell. Biol. 23(15), 5293-5300 (2003).

7 Lee H-S, Barraza-Villarreal A, Hernandez-Vargas $\mathrm{H}$ et al. Modulation of DNA methylation states and infant immune system by dietary supplementation with $\omega-3$ PUFA during pregnancy in an intervention study. Am. J. Clin. Nutr. 98(2), 480-487 (2013).

8 Altucci L, Rots MG. Epigenetic drugs: from chemistry via biology to medicine and back. Clin. Epigenetics 8, 56 (2016).

9 The Academy of Medical Sciences. Stratified, personalised or P4 medicine: a new direction for placing the patient at the centre of healthcare and health education. https://acmedsci.ac.uk/file-download/38266--56e6d483e1d21.pdf

10 Campión J, Milagro FI, Goyenechea E, Martínez JA. TNF- $\alpha$ promoter methylation as a predictive biomarker for weight-loss response. Obesity 17(6), 1293-1297 (2009).

11 Jenke AC, Postberg J, Raine T et al. DNA methylation analysis in the intestinal epithelium - effect of cell separation on gene expression and methylation profile. PLoS ONE 8(2), e55636 (2013).

12 Relton CL, Davey Smith G. Two-step epigenetic mendelian randomization: a strategy for establishing the causal role of epigenetic processes in pathways to disease. Int. J. Epidemiol. 41(1), 161-176 (2012).

13 Lauschke VM, Ivanov M, Ingelman-Sundberg M. Pitfalls and opportunities for epigenomic analyses focused on disease diagnosis, prognosis and therapy. Trends Pharmacol. Sci. doi:10.1016/j.tips.2017.05.007 (2017) (Epub ahead of print). 
(

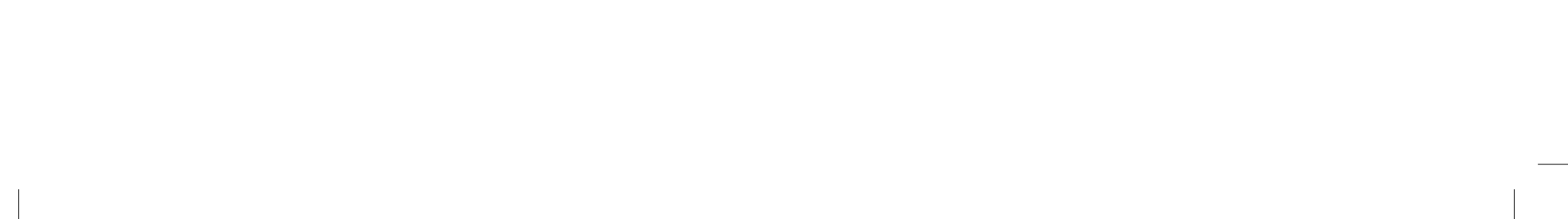

